\title{
A double life cycle: determining tourism development in Macedonia
}

\section{Biljana Petrevska \& Noga Collins-Kreiner}

To cite this article: Biljana Petrevska \& Noga Collins-Kreiner (2016): A double life cycle:

determining tourism development in Macedonia, Journal of Tourism and Cultural Change, DOI: 10.1080/14766825.2016.1150288

To link to this article: http://dx.doi.org/10.1080/14766825.2016.1150288

曲 Published online: 29 Feb 2016.

Submit your article to this journal $\sqsubset x$

Щ Article views: 73

Q View related articles $₫$

View Crossmark data \ 


\title{
A double life cycle: determining tourism development in Macedonia
}

\author{
Biljana Petrevska $^{\mathrm{a}}$ and Noga Collins-Kreiner ${ }^{\mathrm{b} *}$ \\ ${ }^{a}$ Faculty of Tourism and Business Logistics, Goce Delcev University, Stip, Macedonia; \\ ${ }^{b}$ Department of Geography and Environmental Studies, Head of the Haifa and Galilee Research \\ Institute, University of Haifa, Israel
}

(Received 11 April 2015; accepted 13 January 2016)

\begin{abstract}
This article investigates the symptoms of tourism development in Macedonia by applying the Tourism Area Life Cycle (TALC) model. The study explores the political context and the government's role in policy-making and implementation at each TALC stage. It also attempts to assess key arenas of governmental influence on tourism, such as privatization, legislation, tourism promotion, and fiscal policy. To this end, we conducted an analysis of secondary data sources with the aim of assessing the current stage of tourism development. Our analysis indicates that tourism in Macedonia is presently in the development stage but that future decline is still possible. Our general findings indicate an insufficiently developed tourist supply, underlining the importance of taking action as a prerequisite for a well-established tourism planning process. Finally, the study reviews and offers a better understanding of the manner in which Macedonia's tourism policies are changing in a complex region, with the aim of blending top-down decision-making with elements of grass roots involvement in a bid to create a solution to the country's search for a new future.
\end{abstract}

Keywords: TALC model; Macedonia; politics; government role; tourism development

\section{Introduction}

Countries around the world today are designing and adopting strategies, methods, and tools aimed at attracting tourists and achieving a competitive position in the global tourism arena (Avraham \& Ketter, 2015; Huybers, 2007; Pike, 2005; Telfer \& Sharpley, 2008). Tourism, however, is influenced by a large number of social, economic, political, and environmental factors and is therefore extremely diversified in character. For these reasons, tourism planning must be recognized as an extremely complex process burdened by high uncertainty and unexpected influences (Connell, Page, \& Bentley, 2009; Dredge \& Jenkins, 2007; Liu \& Wall, 2006; Ruhanen, 2004; Wall \& Mathieson, 2006).

Like many other studies, this article employs Butler's (1980) Tourism Area Life Cycle (TALC) model as a framework of analysis (Romão, Guerreiro, \& Rodrigues, 2013; Yang, Ryan, \& Zhang, 2014; Zhang \& Xiao, 2014), but pays particular attention to the role of politics and government influence during each stage of tourism development in Macedonia. It also assesses the effects of government regulations and policies on tourism development. This line of inquiry is especially interesting, as tourism is linked to significant processes of social and economic change that are typical of developing countries such as Macedonia,

*Corresponding author. Email: nogack@geo.haifa.ac.il 
which, just two decades ago, emerged as an independent country after years of inclusion within the former Yugoslavia.

Although this paper adds to the current research on tourism in developing countries (Wall \& Mathieson, 2006), its main contribution to the literature lies in its highlighting of the connection between political context and the government's role in policy-making, on the one hand, and each TALC stage, on the other hand, in an effort to provide a better understanding of the complexity of tourism development at its different stages.

The research assessing the development of tourism in Macedonia from this perspective has thus far been limited. Most studies focus on the direct effects of tourism (Petrevska, 2011, 2012a, 2012b, 2013) and pay little or no attention to the role of politics, making Macedonia's specific political environment and its powerful influence on tourism development extremely worthy subjects of tourism research. The Macedonian government has played a number of different roles in this area and also serves as a patron of change, a protector of cultural and natural environments, and a legitimizer of business practices.

Macedonia was selected as the focus of this study because as a new country and an emerging economy, virtually no academic studies have thus far been published on this topic in Macedonia or elsewhere. Another reason for our focus on Macedonia is the fact that political stability and economic development are current priorities of the Macedonian government, and, tourism development, to some extent, serves as an index of political stability in the region.

This article assesses the validity and applicability of the TALC model with regard to the evolution of tourism development in Macedonia and attempts to disentangle the involvement of government and politics in shaping tourism development in the country. The next section offers a brief overview of the literature on TALC and on the role of politics and government influence in tourism, and section three provides selected facts and figures regarding the current state of tourism development in Macedonia. Section four addresses the study's methodology and research frame, and section five presents our main research findings and discussion. The article's final section offers practical remarks aimed at motivating key players in the tourism arena to focus their attention on identifying an effective framework for improving their current modest results and formulating sound economic and tourism policies.

\section{Literature review}

\subsection{TALC research}

The literature contains a large body of work exploring the TALC model, which was first advanced by Butler (1980). TALC, which is known as the classical model for explaining the evolution of tourism, breaks the process down into the phases of exploration, involvement, development, consolidation, and stagnation, followed alternatively by either decline or rejuvenation, resulting in a logistic S-curve. The model presumes that periods of tourism development are followed by growing involvement on the part of local communities and increased impact on the environment and the economy. Indeed, it is fully applicable to already established destinations with long life spans (Butler, 2009) and is often understood as an ideal model of evolution (Weaver, 2006).

Moreover, this useful tool also helps to assess the evolving character of tourism areas and assists in explaining and addressing cycles of economic growth in tourism-dependent areas with environmental constraints (Lozano, Gomez, \& Rey-Maquieira, 2008; Wall, 1982); marketing perspectives (Papatheodorou, 2006); economic, social, and 
environmental issues (Hovinen, 2002; Tooman, 1997); different types of entrepreneurs (Russel, 2006, 2011); the tourist life cycle (Oppermann, 1995); and spatial interaction (Hall, 2006). The TALC model has also been applied to specific destinations and attractions to explain the limitations of using natural phenomena - such as natural parks (Boyd, 2006; Zhong, Deng, \& Xiang, 2008), agro-tourism (Pulina, Dettori, \& Paba, 2006), and salt-mines (Kruczek \& Szromek, 2011) - and local cultural features (Malcolm-Davies, 2006; Meng, Wei, \& Yu, 2011; Russo, 2006) in attracting tourism.

Although the majority of studies have generally tended to support Butler's model, a smaller number indicate that many assessed destinations have not entirely conformed to it (Boyd, 2006; Stansfield, 1978; Weaver, 2000). Some noted specific deviations and were critical of the TALC theory for its simplicity, its lack of precision, and its limited application scale (Aguiló, Alegre, \& Sard, 2005; Prideaux, 2000; Uysal, Woo, \& Singal, 2013). TALC has also been criticized as a mono-parametric procedure due to the fact that its curve is determined only by the number of visitors to the destination and not by other means. Moreover, it has been noted that the TALC model fails to address other relevant non-tourism indicators that are relevant due to the complexity of describing the tourism phenomenon. However, despite the criticism it has sustained over the years, TALC continues to provide a useful framework and starting point for various analyses, and a cornerstone for investigating tourism development, as reflected in its many adaptations (Lagiewski, 2006). For this reason, most researchers agree that the TALC model has played an assisting, facilitative role in tourism planning and management (Berry, 2011; Butler, 2000, 2012; Candela \& Figini, 2012; De Camillis, Raggi, \& Petti, 2010; Getz, 1992; Hovinen, 2002; Russell, 2011).

\subsection{Tourism, politics and the role of governments in tourism development}

Tourism and politics is an over-researched topic with a large number of specialist-authored case studies from around the world that emphasize the linking of theory to practice (Causevic \& Lynch, 2013). The research on the topic has dealt with many different subject areas, including (among others) the tourism business and the travel trade, public policy and tourism, and different aspects of supply and demand (Cavlek, 2002). The different case studies hail from different parts of the world, as partially exemplified in studies on the tourism-supporting activity of public bodies and local governments in Cyprus, Turkey, and Lebanon (Altinay \& Bowen, 2006; Altinay \& Issa, 2006; Sönmez, 1998; Sönmez \& Sirakaya, 2002). The study closest to Macedonia is an article that explores the impact of the context of economic and social renewal in the aftermath of political conflict on tourism development in Bosnia and Herzegovina (Causevic \& Lynch, 2013). Still, although the research dealing with general tourism management and development in post-conflict settings has expanded immensely in recent years, the impact of government activity on tourism development has thus far been lacking.

Government involvement has greatly influenced tourism development, particularly in developing countries with socialist economic systems. Most developing countries are characterized by a scarcity of resources, especially for tourism development, and a private sector that has little experience with the tourism industry (Zhang, King \& Ap, 1999). Governments in developing countries tend to be more actively involved and assume key developmental and operational roles. Therefore, in socialist countries with small or non-existent private sectors, the level of government involvement tends to be greater than in countries with predominantly free enterprise philosophies (Jenkins \& Henry, 1982). 
Jenkins and Henry (1982) make definitional distinctions between passive and active government involvement in tourism in developing countries. Active involvement is seen as a deliberate action by government to favor the tourism sector, whereas passive involvement refers to government action that may have implications for tourism but is not specifically intended for this purpose.

Hall and O'Sullivan (1996) were among the first to propose a model of the tourism policy-making process. They regard the government's role in tourism as an outcome of tourism policy formulation and implementation and posit that the most straightforward way of identifying government roles in the development of tourism is through an analysis of tourism policy. The following analysis of the TALC in Macedonia will touch on these components of tourism policy.

\section{Tourism in Macedonia}

Macedonia has been an independent country since 1991, when it declared independence from the Socialist Federal Republic of Yugoslavia (SFRY), which had consisted of Macedonia, Bosnia and Herzegovina, Croatia, Serbia, Slovenia, and Montenegro. The SFRY was a highly decentralized federation in which the provinces (referred to as 'republics') enjoyed extensive autonomy in conducting tourism policy. The SFRY had no tourism policy at the central level, and each province maintained its own institutions, legislation, and tools concerning tourism policy. Macedonia, geographically located in the central part of the Balkan Peninsula in Southern Europe is a small country that has undergone considerable economic reform but is still less developed than most of the former Yugoslav states (Table 1).

Due to fact that tourism is often regarded as a main vehicle for cultural development and national integration, this sector was identified by the Macedonian authorities as a possible means of micro- and macro-economic impact of various kinds. To this end, a National Strategy for Tourism Development (2009-2013) was prepared with the primary aim of establishing Macedonia as a well-known European travel and tourism destination based on its cultural and natural heritage (Government of the Republic of Macedonia, 2009, p. 3).

In 2012, the direct contribution of travel and tourism to Macedonia's gross domestic product (GDP) was $1.3 \%$, and its total contribution was $4.9 \%$. The same year, travel and tourism provided direct support for 8,000 jobs and indirect support for 28,500 jobs, and accounted for $1.9 \%$ of total investment (WTTC, 2013, p. 1). Thus far, tourism in Macedonia has achieved an average growth rate of $4.64 \%$ per year, exceeding the average growth of the entire economy $(3.12 \%)$. The initial impression made by this sector's modest contribution to the country's GDP, with an average of only $1.7 \%$ per year, must be considered in conjunction

Table 1. General facts for Macedonia.

\begin{tabular}{ll}
\hline Area & $25,713 \mathrm{~km}^{2}$ \\
Population & $2,107,158$ \\
Neighbors & Serbia (north), Bulgaria (east), Greece (south), Albania (west) \\
Capital & Skopje \\
GNI per capita & $\$ 4800$ \\
Government & Parliamentary republic \\
Average inflation rate 2006-2015 & $2.43 \%$ \\
Unemployment rate & $27.9 \%$ \\
Income category & Upper middle income \\
Doing business rank & $31 / 189(2014)$ \\
\hline
\end{tabular}


with the slightly lower average for Central and Eastern Europe (CEE), which stands at 1.6\% (WTTC, 2009, p. 6), and the average participation of tourism employees in the total workforce, which stands at $3.1 \%$ - more than twice the average of the CEE (1.4\% in 2009) (WTTC, 2009, p. 6). Macedonia has also identified tourism as an industry with the potential to promote important economic goals, such as enhancing the foreign export demand for domestic goods and services, generating foreign currency earnings and new employment opportunities, contributing to the repayment of foreign debt, and increasing national revenue.

The total number of tourists in the country has continued to rise. Of the 701,794 tourists in Macedonia in 2013, 302,114 (43\%) were domestic and 399,680 (57\%) were foreign. The year 2013 recorded a total of $2,157,175$ overnight stays, with 1,275,800 (59\%) accounted for by domestic tourists and $881,375(41 \%)$ by foreign tourists. The third quarter of the year (July-September) was clearly dominant in terms of arrivals, accounting for $35.8 \%$ of all recorded arrivals in the country in 2013. The general average length of stay was 3.1 days (4.2 days for domestic tourists and 2.2 days for foreign tourists). In addition to the increased interest of tourists from Turkey, the Netherlands, and Poland, Macedonia's foreign tourists generally come from neighboring countries such as Greece, Serbia, Bulgaria, and Albania.

\section{Research design}

This study has three primary aims: (1) to ascertain Macedonia's tourism life cycle and to identify the country's current stage in the cycle by using secondary data sources; (2) to assess the potential for development and/or decline, based on the findings of the field survey; and (3) to explore the government's role in policy-making and planning regarding tourism development in Macedonia.

To achieve these goals, we have reviewed and analyzed the relevant secondary sources (statistical data, historical and contemporary written sources, and scientific publications), including the use of simplified statistical methods. New insight was also gained from non-written, oral sources, or the knowledge attained by the field-team during the field survey. In this study, which was conducted based on the TALC model (Butler, 1980); total annual tourist arrivals constitute the primary unit of measure for tourism development, as it appears to be the most reliable and comparable. Our data set covers the period 19562013. However, in order to enhance our understanding of the topic at hand, we broke down this overall period into two sub-periods, each with its own TALC: Sub-Period I spans the years 1956-1990, when Macedonia was still an integral part of Yugoslavia, and Sub-Period II (1991-2013) covers more than two decades following independence. Throughout these periods, we conducted a detailed assessment of several key areas of government influence on tourism, such as privatization, legislation, tourism promotion, and fiscal policy.

In addition to the analysis of statistical data, we developed a two-step methodology consisting of (i) rapid assessment and (ii) a field survey. The sampled locations were chosen in accordance with a rapid assessment conducted prior to the field survey based on the collection of data through a literature review. We also developed a framework of criteria for the selection of locations, which included relevance to overall national tourism development, potential for tourism growth, and the possibility of different types of intervention for the enhancement of current tourism development. Moreover, the suitability of each location was also assessed using factors that are crucial for assessing not only tourism destination development but also the level of community involvement and policy implementation. The criteria were designed to cover the following six categories: 
(1) General characteristics - General features, level of autonomy, accessibility, etc.

(2) Social characteristics - Nature of networks, potential for linkages, available resources, political awareness, etc.

(3) Tourism development potential - Tourism supply, information, etc.

(4) Economic factors - Market interest, tourism statistics, etc.

(5) Supporting infrastructure - Health, energy, water, waste, etc.

(6) Elements of dispute - Political conflicts, human rights concerns, etc.

In addition to these criteria, general considerations for the primary aims of the study also played a role. These can be understood as encompassing two primary elements: (i) the development perspective, pertaining to the objective of assessing the potentials for development and/or decline; and (ii) the approach, meaning that the location should allow for synergy with current activities and past experiences. An integrated strengths, weaknesses, opportunities and threats matrix was used to highlight the unique strengths and challenges characterizing each of the selected locations with regard to tourism development and community involvement. This facilitated an analysis of potential success factors and at the same time revealed major threats to tourism development at the specific locations.

Based on these criteria, we selected the following locations in Macedonia: Gevgelija, Bogdanci, Dojran, Mavrovo and Rostuse, Prespa, Krusevo, and Povardarie (the wine route region) (Figure 1). Some of the locations hold value as links in a chain that fills out the supply of nearby locations (e.g. Bogdanci to Gevgelija, Gevgelija to Dojran) or possess potential for the development of facilities (Prespa) and the upgrading of existing services and capacities (Krusevo). Locations such as Ohrid, Struga, Skopje, Bitola, and others were excluded from

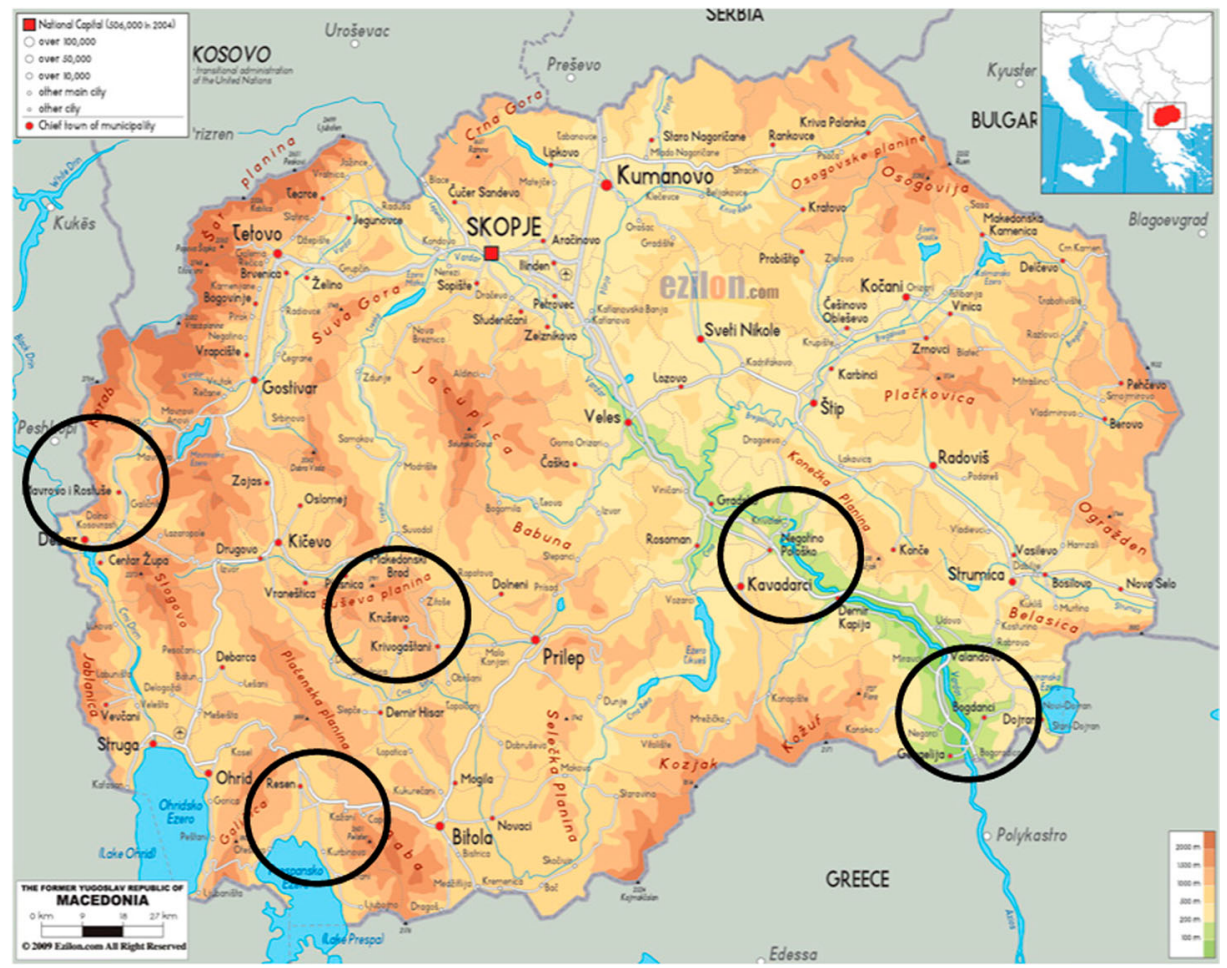

Figure 1. Sampling locations. 
the field survey since they are already well-developed and well-known tourism sites and destinations for summer tourism, cultural tourism, city tourism, and event tourism.

The field survey was conducted between 11 and 19 July 2014. A total of 317 self-administered questionnaires were distributed, out of which 270 were usable and 47 were incomplete, yielding an overall response rate of $85.2 \%$. The target groups, which consisted of respondents reflecting both the supply and demand aspects of tourism and hospitality services, were well informed of the aims of the survey ahead of time in order to avoid any attempt to manipulate the survey process and possibly bias the results. As in Getz (1992), the sample was selected based on the assumption that respondents were tourismknowledgeable and engaged in the tourism process at the local or regional level.

The supply aspect was covered by representatives of service facilities (hotels, motels, private villas, restaurants, and other catering facilities), travel agencies, and local residents. Respondents in this realm included owners/managers of service facilities and travel agencies, as well as local residents who have lived at the destination for more than ten years. Data regarding supply were gleaned from 219 responses, of which $33 \%$ were provided by owners/managers and employees of service facilities, $2.6 \%$ by owners/managers and employees of travel agencies, and $45.5 \%$ by local residents. Data regarding demand were provided by 51 tourists (32 domestic and 19 foreign), representing $18.9 \%$ of the total number of respondents involved in the field survey.

The questionnaire's items were organized into ten primary groups, each consisting of a number of questions. Generally, respondents were asked to determine, on an ordinal scale, the level of tourism development by indicating the most profound negative aspects (with the options of 'not present', 'present in low/medium/high intensity', and 'I do not know'). Due to lack of standardization, limited reliability, and scarce measurement, several tests were applied, including Kruskal-Wallis, Mann-Whitney U, $t$-tests, and Spearman's rank-order correlations.

\section{Findings: analysis of the life cycles}

The first step in achieving the aims of this study was identifying Macedonia's tourism life cycle. Figure 2 offers a visual representation of data on the primary variable employed to this end (total tourist arrivals). This visual impression allows us to reach an important conclusion regarding the major features of Macedonia's life cycle: namely, that Macedonia's life cycle curve exhibits a double cycle sequence known as a cycle-recycle pattern (Rink \& Swan, 1979).

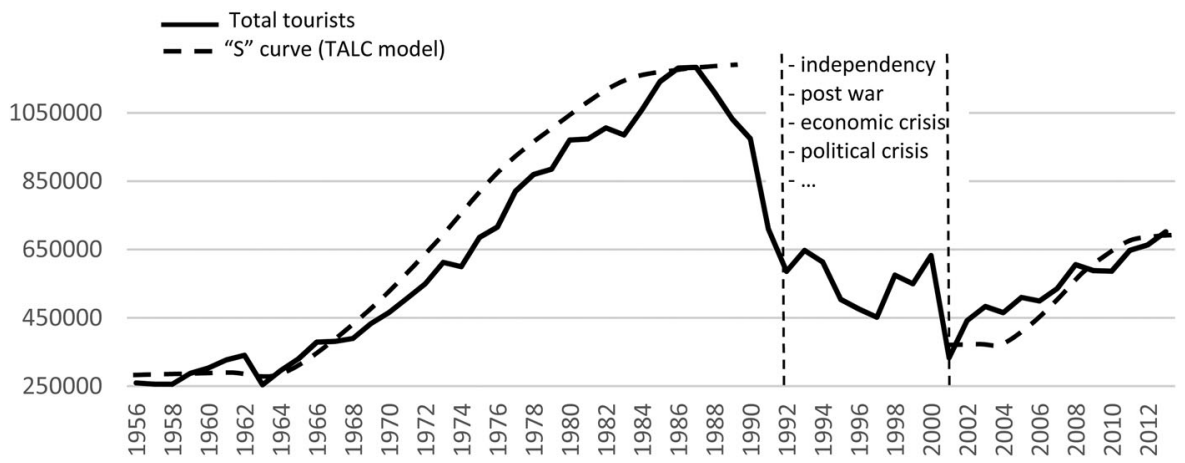

Figure 2. Macedonia's tourism life cycle, 1956-2013. 
To acquire additional in-depth knowledge on the research question, we divided the sample period into two sub-periods and determined TALC curves for each. The period 1991-2001 can be considered a transitional stage, in that it reflects both the decline of the first cycle and, as the period following the independence of Macedonia, the beginning of the second cycle. It was during this period that the previous cycle was discontinued by serious events that had profound negative effects on Macedonia's economy (such as wars in neighboring Serbia, bomb attacks on Kosovo, a refugee crisis, the establishment of a new monetary system and currency, the transformation from a planned to a free-market economy, ethnic conflicts, and political crisis.). This interval was deliberately excluded from the analysis due to fact that during these years, as a result of the above-noted circumstances, Macedonia was not perceived as a safe tourist destination. As a result, it was extremely difficult if not impossible to acquire reliable statistics for this period.

Figure 3 presents a comparison of stages between sub-period I and sub-period II. It can be seen that both sub-periods displayed the same stages of the TALC model, but that their duration differed from one period to the next. This is similar to that found by Romão et al. (2013) when the duration of each stage may differ from destination to destination not only due to the unique evolution of the destination itself but also due to competition.

\subsection{Identifying the life cycle stages for sub-period I (1956-1990)}

Figure 4 reflects that the life cycle for this sub-period fully conforms to the classic TALC model and consists of all the phases (exploration, involvement, development, consolidation, stagnation, and decline).

Before 1956, Macedonia was characterized by an administrative and central planning system of management, and the goals, aims, and objectives of tourism development were focused on domestic tourism. During this period, the government played an active role, and the investment policy generally focused on increasing the capacities of public hotels and establishing catering services and restaurants for the working class. In an effort to support domestic tourism, the government introduced certain reductions in communication taxes.

The first stage explored covers the period 1956-1960, which is characterized by a workers' self-government management system - a system that was applied only in Yugoslavia. This system was characterized primarily by the absence of private ownership and the consequences of this absence for economic activities. The resulting reduced labor productivity had a spillover effect on overall socioeconomic activity. During this stage, the main focus was on individual mass tourists attracted as individuals for independently organized visits. Local residents were not involved and the effects on the national economy were minimal. The total number of tourists was low and there were no public facilities, resulting in a tourism demand that was 30 to $50 \%$ lower than in the involvement stage.

The involvement stage covers the period 1961-1968. During this period, the number of tourists grew primarily due to the government's initiation of various measures and activities

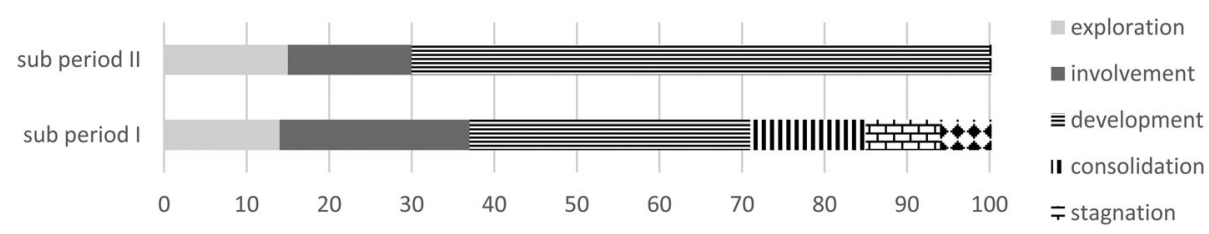

Figure 3. Comparing stages duration between sub-periods. 


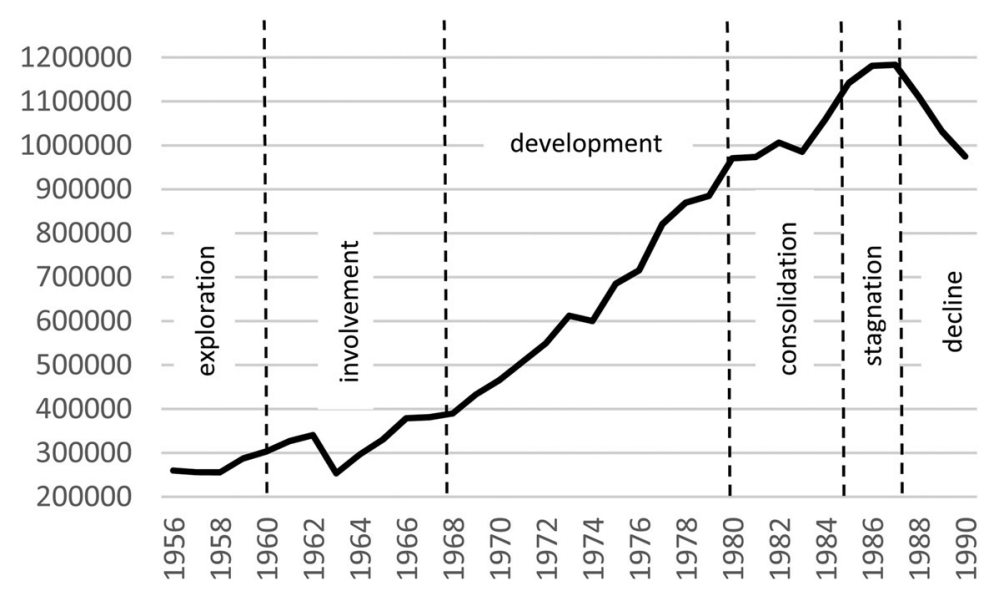

Figure 4. Macedonia's tourism life cycle, sub-period 1956-1990.

for introducing an 'open-door' and 'good-neighbor' policy aimed at enhancing tourism development. The government also built many new accommodation facilities, educated and trained personnel for the tourism industry, invested in tourism infrastructure, allowed free-market price policy, offered domestic tourist discounts (of up to $40 \%$ during the high-season and up to $60 \%$ during the off-season), introduced subsidies to hospitality, granted capital tourism investments, invested in the enhancement of international tourism flow, and other such measures. In 1963, a catastrophic earthquake destroyed the Macedonian capital city of Skopje, which explains the decline in the number of total tourist arrivals. During this period, the government lacked a clearly defined long-term tourism policy and addressed tourism obstacles in a partial and unsynchronized manner by means of short-term ad hoc measures. At the same time, however, the population began to understand the positive effects on their livelihood as a result of the tourist demand for restaurants and accommodations.

During the development stage (1969-1980), tourism was identified as a priority sector for economic development in Macedonia and the government began to engage in significant intervention, including the introduction of tax incentives for stimulating the construction of new tourism facilities, loans, credits, funds for regional development, and other such measures. The main goal during this stage was to initiate and stimulate positive tourism development outcomes. Figure 4 reflects a significant increase in tourist arrivals during this period, indicating that this goal was achieved. The mean growth of tourism demand during this stage was $7.7 \%$, far exceeding the critical $2.5 \%$ threshold identified by Romão et al. (2013) as indicative of high development. During this period, the overall number of tourists was almost equal to the number of permanent residents.

During the consolidation stage, which lasted from 1981 to 1985 , the total number of tourists grew by $30 \%$ in comparison to the development phase, indicating the full development of tourism functions. The incidence of this stage, as noted by Martin and Uysal (1990), is often defined by physical, psycho-sociological, and sociological criteria. This period is characterized by activities and measures aimed at encouraging the development of foreign tourism, such as the provision of financing for promotion expenses; favorable credit for the construction of accommodation facilities for less developed municipalities; the stimulation of foreign exchange earnings; and enrichment of the tourism supply. 
The short period spanning the years 1986-1988 marked the stagnation stage. During this two-year period, tourism reached its height of 1.2 million tourists before entering into decline stage (1989-1990), which marked the final stage of the TALC experienced by Macedonia prior to independence. It was characterized by a decline in the total number of tourists (an average of 6.4\%), decreasing tourist expenditures, a drop in the quality of tourist product, social problems, instability in the surrounding region, negative political conditions (national and regional), and threats posed by numerous other exogenous factors. The decline in this case was the result of the beginning of the armed conflict among the components of the state of Yugoslavia which ended in its disintegration.

\subsection{Identifying the life cycle stages for sub-period II (1991-2013)}

Figure 5 illustrates the life cycle of Macedonia as a tourist area as a function of total tourist arrivals during the second sub-period of 1991-2013, which represented more than twenty years of independence. As noted above, the period 1991-2001 marked the decline stage of the previous cycle due to the destructive effect of a large number of major destabilizing events that discontinued the cycle and had a detrimental impact on tourism development (such as the collapse of former Yugoslavia, the transition process, various reforms, political instability, armed conflicts in neighboring countries, economic crisis, sanctions, blockades, internal ethnic conflicts, and socioeconomic restructuring.). For this reason, the second cycle curve for this sub-period begins only after 2001.

Figure 5 clearly reflects extreme decline in 1992, 1997, and 2001. By 2001, generally speaking, the role of the government in policy-making and implementation at each TALC stage had changed considerably. Specifically, the active role was transformed and tourism was marginalized. Tourism was stagnated through the end of the 1990s as a result of a slow recovery and transformation process, a lack of coordination between the key tourism players, a lack of foreign investments, and other such factors. Moreover, tourism during this period faced many challenges in the form of unfavorable conditions in the region. Most importantly, perhaps, has been the fact that many ethnic conflicts have taken place within the territory of the former Yugoslavia, such as the war in Slovenia (1991), the Croatian War of Independence (1991-1995), the Bosnian War (1992-1995), and the war in Kosovo (1998-1999), including the NATO bombing. As a result, the region was forced to comprehensively rebuild and reform the economies of its countries to remedy the

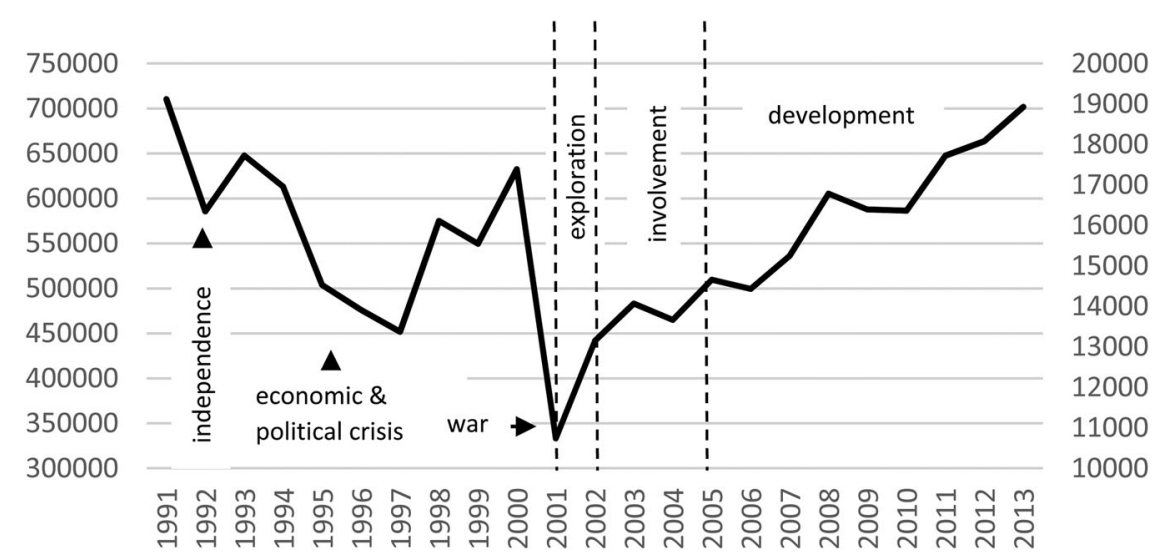

Figure 5. Macedonia's tourism life cycle, sub-period 1991-2013. 
absence of global trade, the marginalized role of the private sector, and the dismantled regulations and the stifled business environment in which they resulted. The process of structural transformation began to stall, although the growth within the region was driven more by ample global liquidity than real economic progress. The weakness of the region's economic model was reflected in high unemployment rates of over $20 \%$, which resulted in a sharp decline in tourist flows. In 2000, the number of foreign visitors was 224,016 , accounting for $35.4 \%$ of total arrivals.

Following the 2001 breakdown stemming from the ethnic conflict in Macedonia, the government redefined tourism as an important factor for economic development and placed it on its agenda as an issue of high priority. With this, tourism was once again regarded as a means of accelerating economic development, and the government delineated its approach by formulating a medium and long-term tourism policy, preparing and implementing a tourism development plan, enacting tourism legislation, assuring tourism quality, and other such measures. In contrast to the previous sub-period, in which Macedonia's life cycle fully conformed to all the stages of the classic TALC model, this second sub-period contained only three stages: exploration, involvement, and development (Figure 5).

During the exploration stage (2001-2003), tourism in Macedonia was characterized by low publicity, resulting in scarce visitation. During this period, the average annual number of tourists was 387,510 , or approximately $30 \%$ lower than the average number of tourists recorded during sub-period II (543,146 tourists). Tourism infrastructure and facilities were inadequate, advertising was unconvincing, and the tourist activity growth rate was low and based chiefly on individual trips. The country also suffered from a lack of specific tourismoriented services. Overall, tourism had no substantial impact on the lives of residents.

During the involvement stage (2004-2005), tourism awareness increased significantly among the local population and tourism actors, helping to shape the tourism market. This upward trend was reflected in international tourist arrivals, which almost doubled between 2001 and 2004, from 98,946 to 165,306. As a result, Macedonia's average annual number of tourists was $22.3 \%$ greater during the involvement stage than the exploration stage. Although showing growth up to the average of 474,083 tourists, it was still 1.2 times lower compared to the average number of tourists registered in the sub-period I. The local environment also improved significantly (in political and economic terms), which also contributed to the expansion and enhancement of the tourism facility. In this manner, the total number of establishments increased from 4 in 2002 to 10 in 2005 , while the number of beds in apartments, family apartments, and rooms increased from 160 to 517 (State Statistical Office, 2010, pp. 12-13).

The development stage (2005-2013) was characterized by a progressive increase in the number of tourists, attracted by persuasive advertising and increased promotion. The budget expenditures allocated for implementation of the tourism promotion program increased from approximately $€ 100,000$ in 2004 (involvement stage) to $€ 2.3$ million in 2013 (Government of the Republic of Macedonia, 2012). As a result, Macedonia recorded a record number of tourists in 2013 with 701,794 tourists in total, including 399,680 foreign tourists and 302,114 domestic tourists. The average number of tourists during the development stage was 593,080, or 1.3 times higher than the average number of tourists recorded during the involvement stage and 1.5 times higher than the average number of tourists recorded during the exploration stage. The data representing the international tourism demand are also consistent with the above conclusion, with an average of 276,062 foreign tourists during the development stage in comparison to 110,904 during the exploration stage and 161,499 during the involvement stage. The year 2013 reflected the highest number of foreign tourists in Macedonia's history since independence with 399,680 
foreign tourists, which was 3.3 times higher than the number of foreign tourists recorded in 2002 (the best year in the exploration stage) and 2.4 times higher than the number recorded in 2004 (the best year in the involvement stage).

Auxiliary tourism facilities and services also improved and investments were made in new ventures. Tourism services and activities began to grow at a quicker pace, new services were provided in the form of organized trips, and tourism in the country began to have an impact on local residents. This stage also witnessed the continued growth of tourism flows, particularly in international demand from Western European countries and regional neighbors. The competition presented by neighboring countries and within the region can be summed up as follows. Although in terms of size and population Macedonia is perhaps most comparable to Albania and Slovenia, in terms of tourism indicators such as arrivals, overnights stays, and percentage of GDP, it lags far behind these countries (Government of the Republic of Macedonia, 2009, p. 16). According to the National Strategy for Tourism Development (Government of the Republic of Macedonia, 2009, p. 17), Macedonia's tourism product consists of beach (lake-based) tourism, cultural heritage, mountains, and rural tourism. That being the case, Macedonia appears to be competing directly with Albania and Serbia in the realm of cultural heritage, mountains, and rural tourism, while Croatia, Slovenia, and Bulgaria are focused on spa and wellness tourism and sea tourism. Macedonia's travel and tourism competitiveness index, which has changed only slightly over the years, is not very promising. Macedonia was ranked 83rd out of 124 countries in 2007, 75th out of 140 countries in 2013, and 82nd out of 141 countries in 2015. Indeed, the vast majority of countries in the region are significantly better ranked than Macedonia, as in the cases of Croatia (33rd), Slovenia (39th), Bulgaria (49th), and Montenegro (67th) (World Economic Forum [WEF], 2015, p. 5). Of its neighboring countries, only Serbia $\left(95^{\text {th }}\right)$ and Albania (106th) are ranked lower than Macedonia, while Bosnia and Herzegovina is not covered by the Travel and Tourism Competitiveness Report for 2015 (WEF, 2015, p. 8).

During the development stage, the number of tourists increased by $33.7 \%$, with an average annual growth rate of $3.75 \%$. The trend of increasing arrivals was followed by a more moderate $21.8 \%$ increase in overnights and an average annual growth rate of $2.4 \%$, and the share of neighboring economies in terms of international tourists was $40.8 \%$ (OECD, 2012). The data suggest a lack of connectivity between increased arrivals and overnights, indicating a relatively short average duration of stay (only 3.5 days). Addressing this situation has required the creation of a comprehensive and well-designed supply of diversified tourism products by including various events associated with culture and tradition, which has also served to promote the country as an attractive tourism destination for the surrounding region. This enhancement of the tourism supply has contributed to increases in the number of total tourists and overnights, the average length of stay, reduced seasonality, and the promotion of sustainable development. In particular, the increased number of foreign tourists has helped to introduce various events of local, regional, and national character, with an eye toward their international expansion.

Also during the development stage, the government significantly changed its role in a qualitative manner, by continuing intervention but limiting it only to certain high priority areas such as funding tourism promotion, crediting capital tourism capacities, stimulating tourism income, enhancing tourism supply, and initiating tourism networking. When it comes to development processes and the improvement of general infrastructure, one of the government's most significant commitments has been the modernization of the country's airport infrastructure. In 2010, two international airports - Alexander the Great in Skopje and St. Paul the Apostle in Ohrid - were handed over to the Turkish company 
TAV by concession. Based on an investment of over $€ 100$ million, the airports have been fully modernized, contributing to a $75 \%$ increase in the number of passengers and a more than doubling of the number of airlines. In this way, as pointed out by Cohen (1972), individual mass tourism has slowly shifted to organized mass tourism. In addition, the government decided to improve tourism promotion and in 2008 established the Agency for Support and Promotion of Tourism in Macedonia, which, in 2013, began drafting new pieces of tourism-related legislation, such as legislation on tourism development zones.

All this has resulted in the current development, out of which we can conclude that during this stage, several crucial government initiatives were undertaken, such as large investments in infrastructure, massive promotion, extended tourism legislative and organized travel on the international level. We can also observe that the development stage lasted much longer during sub-period I (1956-1990).

Macedonia has not reached the consolidation stage and is therefore yet to experience stagnation. However, this may begin when the rate of tourists' visits starts to decrease, despite growing in absolute figures. During this phase, the number of tourists may exceed the number of inhabitants, at least at some times of the year, pointing to the presence of a tourism-based economy (Garay \& Cànoves, 2011). This would also mean that tourism is economically important for the destination, but that the growth rates are low. Generally, in these final stages, the tourism market is saturated and the introduction of innovative itineraries is a priority for the promotion of diversified tourist products. The national tourism system, therefore, is in need of strengthening supported by reminder-oriented advertising and the implementation of new strategies for tourism development through the involvement of local stakeholders (Brooker \& Burgess, 2008; Kozak \& Martin, 2012).

\subsection{Testing future development}

The results of the survey allow us to draw some interesting conclusions regarding the potential for a development and/or decline stage. Specifically, the analysis of statistical data regarding supply, demand, and other, more general factors reveals several symptoms of the development stage assessed for the period 2005-2013 (Table 2) and of a potential decline stage in the future (Figure 5).

Many of the indicators presented in Table 2 confirm the occurrence of significant development during 2005-2013, as reflected in the increase of all calculated mean annual growth rates. The growth rate of total tourist arrivals, which far exceeds the development threshold of $2.5 \%$, also confirms tourism development in the country (Romão et al., 2013), as does the positive rate of total tourist overnights (1.8\%). Also indicative of development is the encouraging data regarding supply, which reflects growth of $1 \%$ and $1.9 \%$ in hotels beds and hotels rooms respectively. On the other hand, we note a decline in the indicator for the average stay of local tourists, which during the development stage stood at 3.5 days,

Table 2. Indicators for development stage (as of 2005).

\begin{tabular}{lll}
\hline Indicator & Status & \multicolumn{1}{c}{ Comments } \\
\hline Total tourist arrivals & Increase & Mean annual growth rate of $4.8 \%$ \\
Total tourist overnights & Increase & Mean annual growth rate of $1.8 \%$ \\
Average stay & Decrease & 3.5 days $(-14.6 \%)$ \\
Net occupancy rate of hotel beds & Stagnation & $18.7 \%(2013)$ \\
Accommodation capacity (hotel beds) & Increase & Mean annual growth rate of $1 \%$ \\
Accommodation capacity (hotel rooms) & Increase & Mean annual growth rate of $1.9 \%$
\end{tabular}


representing a decline of $14.6 \%$ from the involvement stage. We also note the stagnation reflected in the indicator for the net occupancy of hotel beds (particularly over the past three years), which may be interpreted as indicating the possibility of decline.

Figure 6 presents the indicators for potential decline assessed by the respondents surveyed in the field research. The summarized survey's results actually may present the potential symptoms for a slow-down in the supply and demand side when referring tourism development.

The following indicators were most commonly selected, with between $75 \%$ and $82 \%$ of respondents denoting presence at a medium to high level of intensity: (1) increasing competition from regional tourism markets; (2) unfavorable economic conditions; (3) lack of support in tourism promotion (on the local and national government level); (4) high prices compared to regional tourism markets; and (5) low interest in work in the tourism sector. Four-fifths of the respondents identified the involvement of tour operators as being of medium significance. The results also reflected significant variation in respondents' attitudes toward the indicators regarding the seasonal concentration of tourism flows, as well as the lack of adequate general and tourism infrastructure, which most probably stems from different understandings of the issues. Nonetheless, it is interesting to note that a number of significant factors of sustainable tourism development - such as political environment, government financial support, and the role of tourism mediators - were indicated by only a small number of respondents. This does not, however, detract from the importance attributed to the low level of involvement of tour operators, the lack of subsidies for tourism enterprises on the national level, and adverse external political conditions as factors that may profoundly affect tourism development.

The above-noted factors can be understood as possible symptoms, to varying degrees, of a potential slow-down in the development stage or the onset of decline in further tourism development in Macedonia. This assessment is supported by the negative view reflected by the overall average score regarding the future outlook for Macedonia's hotel market (Horwath HTL, 2014).

\section{Discussion and conclusions}

\subsection{The TALC's applicability to Macedonia}

The main purpose of the paper was to assess the applicability of the TALC model to the historical development of tourism in Macedonia. Our research revealed a double cycle sequence:

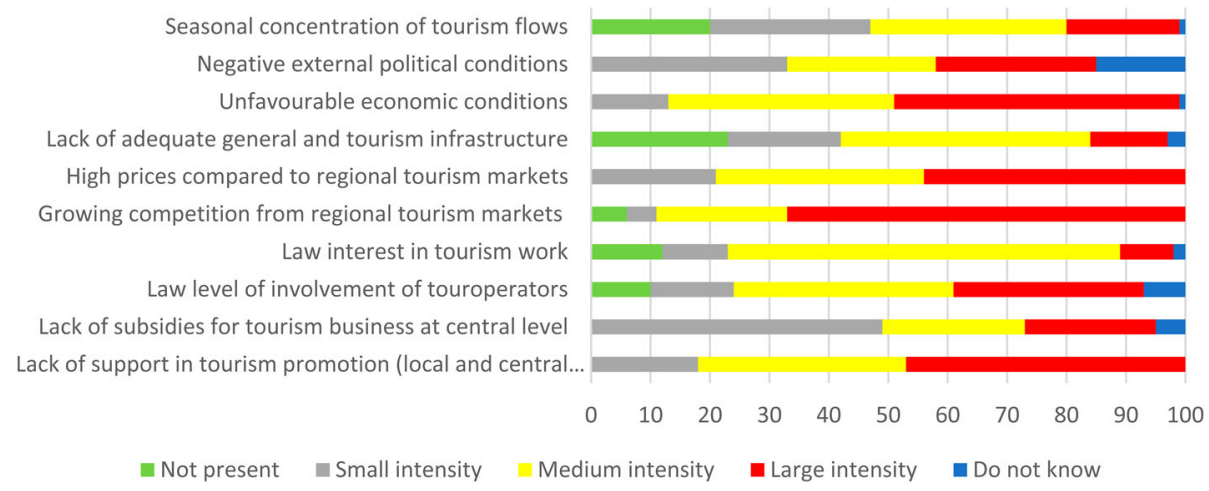

Figure 6. Main summarized survey's results. 
(1) The first cycle occurred in the context of a centrally planned economy, and reflected the stages of exploration (1956-1960), involvement (1961-1968), development (1969-1980), consolidation (1981-1985), stagnation (1986-1988) and decline (1989-1990).

(2) The second cycle was a free-market cycle reflecting only three stages: exploration (2001-2003), involvement (2004-2005), and development (2005-2013).

Our assessment suggests that Macedonia is currently in the 'development' stage of the TALC, attracting sufficient visitors and simultaneously maintaining control over undesirable social impacts such as crime, overcrowding, rising prices, and local hostility. Indeed, our analysis indicates a dynamic and ongoing increase in total tourist arrivals (averaging $4.8 \%$ ), hotel beds (1\%), and hotel rooms (1.9\%). Generally speaking, the country has reached a state of tourism maturity. Our research found the tourism market area to be well defined, though still not sufficiently formed in some parts. The data regarding the general development of tourism, catering, and services are indicative of increase in almost all areas, as reflected in the number of catering business units (an average of 2.2\%), employees (3.1\%), and turnover (14.5\%) (State Statistical Office, 2015, p. 592). Consequently, we may conclude that the local residents have successfully endured the involvement stage. However, they are currently facing rapid decline in their control and involvement, as larger and more modern facilities move in to provide accommodations. Another finding is that natural and cultural tourist attractions are being developed and marketed, but in an insufficient manner. We believe that the current development will continue for a limited period. The study identified a number of indicators for the continuation of this stage but also identified risks of possible decline.

\subsection{The government's role in tourism}

This article's main theoretical contribution to the literature lies in its highlighting of the connection between political context and the government's role in policy-making, on the one hand, and each TALC stage, on the other hand, in an effort to provide a better understanding of the complexity of tourism development at its different stages.

Unlike most transition countries which have opted for mass privatization schemes, Macedonia has adopted a model of case-by-case privatization. Privatization in the country began in mid-1993 with Parliament's enactment of The Law on Transformation of Enterprises with Social Capital. Initially, the privatization of tourism and hospitality enterprises represented only a small fraction of the entire privatization program. With only 70 enterprises and 5,890 employees in this sector at the beginning of the process, its privatization was only a marginal issue within the broader, overall picture of the 1,216 enterprises requiring privatization (with their 228,850 employees).

Although the actual implementation of the privatization program was delayed until the beginning of 1995, the process progressed at an impressive pace and was almost completed by the end of 1997, after the formal privatization of 1,132 enterprises ( $93 \%$ of the total). In contrast, privatization in the tourism and hospitality sector has advanced slowly and has been completed for only $56 \%$ of the total number of enterprises.

The analysis of both life cycles indicates that the Macedonian government's role in tourism has been an outcome of tourism policy formulation and implementation and that the policy-making process has consisted of different modes and stages (Hall \& O'Sullivan, 1996). During these periods, government activity involved not only positioning tourism in Macedonia within the global strategic arena in an appropriate manner but also the crucial 
implementation of a tourism development plan aimed at achieving sustainable growth of the tourism industry. This was accomplished by means of various measures and activities aimed at supporting international tourism and redirecting domestic tourists toward domestic tourism destinations. In order to strengthen Macedonia's tourism competitiveness, the first national web tourism portal (www.exploringmacedonia.com) was launched in 2005 as a public-private partnership between an international donor and the Ministry of Economy. Several other private initiatives are also currently serving as additional tourism portals, thus supporting the country's tourism profile.

Furthermore, in 2008, in an effort to spark positive trends in the tourism domain, the Macedonian government established the Agency for Tourism Support and Promotion with the primary task of promoting tourism resources and capacities, particularly at the international level. The same year, the government launched its first multiple stage promotion campaign titled 'Macedonia - Timeless', with advertisements broadcasted on the internationally prominent CNN television news network. In late 2012, the government established the first electronic online shop of its kind in Macedonia (www.macedonianhandicrafts.mk), which, in addition to enhancing the competitiveness of small and medium-sized enterprises, has helped to enhance the poorly developed tourism supply.

Government involvement in Macedonia was found to greatly influence tourism development, and the government was found to have played extremely influential developmental and operational roles in all the TALC stages. These findings are consistent with the claims in the literature that 'active governments' also exist in other developing countries with socialist economic systems (Jenkins \& Henry, 1982; Zhang et al., 1999).

We also analyzed the 'active involvement' (Jenkins \& Henry, 1982) of the Macedonian government, which consisted of deliberate action aimed at favoring the tourism sector. Despite the slight difference observed in the role played by the government following independence, the Macedonian government's active involvement in tourism development remains strong.

\subsection{Theoretical contributions}

Like many other studies, this article employs Butler's (1980) TALC model as a framework of analysis (Romão et al., 2013; Yang et al., 2014; Zhang \& Xiao, 2014). However, it also pays particular attention to the role of politics and government influence during each stage of tourism development in Macedonia, and in so doing adds another dimension to the current research on tourism in developing countries. As noted above, its major contribution to the literature lies in its highlighting of the linkage between political context and government policy, on the one hand, and each TALC stage, on the other, for the purpose of better understanding the complexity of tourism development at its different stages. The research assessing the development of tourism from this perspective has thus far been limited. Most studies focus on the direct effects of tourism and pay little or no attention to the role of politics. In accordance with Hall and O'Sullivan (1996), our findings indicate that the government's role in tourism has been an outcome of tourism policy formulation and implementation and that the most straightforward way to identify government roles in the development of tourism is through an analysis of tourism policy.

This article is consistent with many other articles that have found the model to be fully applicable and able to accommodate a wide variety of factors, such as economic growth (Lozano et al., 2008; Wall, 1982); marketing perspectives (Papatheodorou, 2006); economic, social, and environmental questions (Hovinen, 2002; Tooman, 1997); different types of entrepreneurs (Russel, 2006, 2011); the life cycle of tourists (Oppermann, 
1995); and spatial interaction (Hall, 2006). In this context, we have found it to also be applicable to political dimensions and the role of government. On this basis, in agreement with most researchers who have considered the issue (Berry, 2011; Butler, 2000; 2012; Candela \& Figini, 2012; De Camillis et al., 2010; Getz, 1992; Hovinen, 2002; Lagiewski, 2006; Russell, 2011), we conclude that, despite the criticism it has sustained over the years, TALC continues to provide a useful framework and starting point for various analyses and a cornerstone for investigating tourism development.

\subsection{Recommendations, limitations, and future research}

Supporting and sustaining the current development stage will require government intervention in a number of ways, particularly by fostering the evolution of a more competitive tourism sector and by facilitating systematic change through the improvement of the tourist product and the strengthening of the role of the private tourism and hospitality sector. In order to make tourism more competitive, the following fundamental strategic improvements should be instituted.

First, efforts should be made to make tourism fully recognizable and to improve the current marketing strategy. The focus should be on promotion, mainly through the introduction of new innovative approaches. The second strategic measure recommended for improving tourism competitiveness is to strengthen the coordination between the central and local governments, in addition to other tourism players from the private sector. The objectives and aims delineated by the tourism development plans and programs must be fully implemented, regardless of the level of implementation. The expectations of all tourism suppliers must conform to the expectations of tourists and travelers who visit Macedonia. To this end, it is recommended to launch a series of Tourism Awareness Program Activities (forums and debates) to raise awareness of the importance of tourism for Macedonia's development.

Despite the indicators of positive tourism development, our findings suggest that the key players must nonetheless pay close attention to overcoming the potential threats posed by the unfavorable attributes of the Macedonian tourism industry. In this way, analysis in accordance with the TALC model can help management take appropriate measures to achieve better balanced tourism development in the country.

This article underscores the importance of continuous, systematic analysis of the tourism sector as a factor to be considered by all tourism actors responsible for creating development strategies in Macedonia. Our theoretical analysis identifies symptoms of potential decline, and our primary conclusions reflect the urgent need to undertake serious measures - including strategic planning for tourism improvement - to enhance tourism development in Macedonia in order to avert such an eventuality.

Our research was limited by several factors that can also serve as productive starting points for future work. First, it employed a relatively small set of indicators and could be enhanced by the addition of additional significant indicators to better assess the country's stage of development. Because cross-sectional data were collected using only a questionnaire survey, the research may also suffer from common method variance effect. As our research was characterized by a relatively small sample size, future work could focus on increasing the number of respondents and other aspects of investigation. Finally, instead of using one model, future research could employ multiple models and theories relevant to the tourism planning process.

Notwithstanding the difficulties involved with using the TALC model to assess the evolution of tourism in Macedonia, this article helps us to better understand the symptoms and indicators upon which the serious redesigning of the national tourism development 
strategy should be based. Overall, the research generated useful findings and points to valuable directions for further work.

\section{Disclosure statement}

No potential conflict of interest was reported by the authors.

\section{References}

Aguiló, E., Alegre, J., \& Sard, M. (2005). The persistence of the sun and sand tourism model. Tourism Management, 26(2), 219-231.

Altinay, L., \& Bowen, D. (2006). Politics and tourism interface: The case of Cyprus. Annals of Tourism Research, 33(4), 939-956.

Altinay, L., \& Issa, I. A. (2006). Impacts of political instability on tourism planning and development: The case of Lebanon. Tourism Economics, 12(3), 361-381.

Avraham, E., \& Ketter, E. (2015). Tourism marketing for developing countries: Media strategies for battling stereotypes. Houndmills, Basingstoke, UK: Palgrave Macmillan.

Berry, T. (2011). The predictive potential of the TALC model. In R. Butler (Ed.), The tourism area life cycle: Conceptual and theoretical issues (pp. 254-279). Bristol, UK: Channel View Publications.

Boyd, S. (2006). The TALC model and its application to natural parks: A Canadian example. In R. Butler (Ed.), The tourism area life cycle, Vol. 1: Applications and modifications (pp. 119-138). Clevedon: Channel View.

Brooker, E., \& Burgess, J. (2008). Marketing destination Niagara effectively through the tourism life cycle. International Journal of Contemporary Hospitality Management, 20(3), 278-292.

Butler, R. (1980). The concept of a tourist area cycle of evolution. Implications for management of resources. Canadian Geographer, 24(1), 5-12.

Butler, R. (2012). Mature tourist destination: Can we recapture and retain the magic? In F. Vera and I. Rodriguez (Ed.), Renovación y reestructuración de destinos turísticos en áreas costeras. Marco de analisis, procesos, instrumentos y realidades (pp. 19-36). Valencia, Spain: Universitat de València.

Butler, R. W. (2000). The resort cycle two decades on. In B. Faulkner, G. Moscardo, \& E. Laws (Eds.), Tourism in the 21st century: Reflections on experience (pp. 284-299). New York: Addison Wesley Longman.

Butler, R. W. (2009). Tourism in the future: Cycles, waves or wheels? Futures, 41(6), 346-352.

Candela, G., \& Figini, P. (2012). The economics of tourism destinations. Berlin and Heidelberg: Springer-Verlag Publications.

Causevic, S., \& Lynch, P. (2013). Political (in)stability and its influence on tourism development. Tourism Management, 34, 145-157.

Cavlek, N. (2002). Tour operators and destination safety. Annals of Tourism Research, 29(2), 478-496.

Cohen, E. (1972). Towards a sociology of international tourism. Social Research, 39, 164-182.

Connell, J., Page, S. J., \& Bentley, T. (2009). Towards sustainable tourism planning in New Zealand: Monitoring local government planning under the Resource Management Act. Tourism Management, 30(6), 867-877.

De Camillis, C., Raggi, A., \& Petti, L. (2010). Tourism LCA: State-of-the-art and perspectives. International Journal of Life Cycle Assessment, 15, 148-155.

Dredge, D., \& Jenkins, J. M. (2007). Tourism planning and policy. Milton: John Wiley \& Sons.

Garay, L., \& Cànoves, G. (2011). Life cycles, stages and tourism history: The Catalonia (Spain) experience. Annals of Tourism Research, 38(2), 651-671.

Getz, D. (1992). Tourism planning and destination lifecycle. Annals of Tourism Research, 19(4), $752-770$.

Government of the Republic of Macedonia. (2009). National strategy on tourism development 2009-2013. Skopje, Macedonia: Ministry of Economy.

Government of the Republic of Macedonia, Ministry of Economy. (2012). Program for tourism promotion for 2013. Skopje, Macedonia: Ministry of Economy. 
Hall, C. M. (2006). Space-time accessibility and the TALC: The role of geographies of spatial interaction and mobility in contributing to an improved understanding of tourism. In R. Butler (Ed.), The tourism area life cycle, Vol. 2: Conceptual and theoretical issues (pp. 83-100). Clevedon: Channel View.

Hall, C. M., \& O’Sullivan, V. (1996). Tourism, political stability and violence. In A. Pizam \& Y. Mansfeld (Eds.), Tourism, crime and international security issues (pp. 105-121). New York: Willey.

Horwath HTL. (2014). Global hotel market sentiment survey, March 2014. Zagreb: Horwath HTL.

Hovinen, G. R. (2002). Revisiting the destination lifecycle model. Annals of Tourism Research, 29(1), 209-230.

Huybers, T. (2007). Tourism and developing countries. Cehltenham, UK: Edward Elgar Publishing.

Jenkins, C. L., \& Henry, B. M. (1982). Government involvement in tourism in developing countries. Annals of Tourism Research, 9(4), 499-521.

Kozak, M., \& Martin, D. (2012). Tourism life cycle and sustainability analysis: Profit-focused strategies for mature destinations. Tourism Management, 33, 188-194.

Kruczek, Z., \& Szromek, A. R. (2011). Using R. W. Butler's model to interpret the development of tourist attractions based on the example of the salt mine in Wieliczka. Folia Turistica, 25 (1), 249-263.

Lagiewski, K. M. (2006). The application of the TALC model: A literature survey. In R. W. Butler (Ed.), The tourism area life cycle, vol. 1: Applications and modifications (pp. 27-50). Clevedon: Channel View Publications.

Liu, A., \& Wall, G. (2006). Planning tourism employment: A developing country perspective. Tourism Management, 27(1), 159-170.

Lozano, J., Gomez, C., \& Rey-Maquieira, J. (2008). The TALC hypothesis and economic growth. Tourism Economics, 14(4), 727-749.

Malcolm-Davies, J. (2006). The TALC and heritage sites. In R. Butler (Ed.), The tourism area life cycle, Vol. 1: Applications and modifications (pp. 162-180). Clevedon: Channel View.

Martin, B. S., \& Uysal, M. (1990). An examination of the relationship between carrying capacity and the tourism lifecycle: Management and policy implications. Journal of Environmental Management, 31, 327-333.

Meng, Z., Wei, Y., \& Yu, Y. (2011). On life cycle of cultural heritage engineering tourism: A case study of Macau. Systems Engineering Procedia, 1, 351-357.

OECD. (2012). Tourism trends and policies 2012. Paris: OECD publishing.

Oppermann, M. (1995). Travel life cycle. Annals of Tourism Research, 22(3), 535-552.

Papatheodorou, A. (2006). TALC and the spatial implications of competition. In R. Butler (Ed.), The tourism area life cycle, Vol. 1: Applications and modifications (pp. 67-82). Clevedon: Channel View.

Petrevska, B. (2011). Tourism in the global development strategy of Macedonia: Economic perspectives. UTMS Journal of Economics, 2(1), 101-108.

Petrevska, B. (2012a). The role of government in planning tourism development in Macedonia. Innovative Issues and Approaches in Social Sciences, 5(3), 118-133.

Petrevska, B. (2012b). Economic impacts of tourism: The evidence of Macedonia. The Young Economists Journal, 18, 174-181.

Petrevska, B. (2013). Tourism contribution to economic development in Macedonia. Economy and Market Communication Review, 3(2), 231-244.

Pike, S. (2005). Tourism destination branding complexity. Journal of Product \& Brand Management, $14(4), 258-259$.

Prideaux, B. (2000). The resort development spectrum (a new approach to modeling Resort development). Tourism Management, 21, 225-240.

Pulina, M., Dettori, D., \& Paba, A. (2006). Life cycle of agrotouristic firms in Sardinia. Tourism Management, 27, 1006-1016.

Rink, D. R., \& Swan, J. E. (1979). Product life cycle research: A literature review. Journal of Business Research, 7(3), 219-242.

Romão, J., Guerreiro, J., \& Rodrigues, P. (2013). Regional tourism development: Culture, nature, life cycle and attractiveness. Current Issues in Tourism, 16(6), 517-534.

Ruhanen, L. (2004). Strategic planning for local tourism destinations: An analysis of tourism plans. Tourism and Hospitality Planning and Development, 1(3), 239-253. 
Russel, R. (2006). The contribution of entrepreneurship theory to the TALC model. In R. Butler (Ed.), The tourism area life cycle, Vol. 2: Conceptual and theoretical issues (pp. 105-123). Clevedon: Channel View.

Russell, R. (2011). The contribution of entrepreneurship theory to the TALC model. In R. Butler (Ed.), The tourism area life cycle: Conceptual and theoretical issues (pp. 105-123). Bristol, UK: Channel View Publications.

Russo, A. (2006). A re-foundation of the TALC for heritage cities. In R. Butler (Ed.), The tourism area life cycle, Vol. 1: Applications and modifications (pp. 139-161). Clevedon: Channel View.

Sönmez, S. F. (1998). Tourism, terrorism, and political instability. Annals of Tourism Research, 25(2), 416-456.

Sönmez, S. F., \& Sirakaya, E. (2002). A distorted destination image? The case of Turkey. Journal of Travel Research, 41(2), 185-196.

Stansfield, C. (1978). Atlantic City and the resort cycle. Annals of Tourism Research, 5(2), 238-251.

State Statistical Office of the Republic of Macedonia. (2010). Statistical review: Accommodation capacity in catering trade and services. Skopje, Macedonia: State Statistical Office of the Republic of Macedonia.

State Statistical Office of the Republic of Macedonia. (2015). Statistical yearbook for 2014. Skopje.

Telfer, D. J., \& Sharpley, R. (2008). Tourism and development in the developing world. Abingdon: Taylor \& Francis.

Tooman, L. A. (1997). Application of the lifecycle model in tourism. Annals of Tourism Research, 24 (1), 214-234.

Uysal, M., Woo, E. \& Singal, M. (2013). The tourist area life cycle (TALC) and its effect on the quality-of-life (QOL) of destination community. In M. Uysal, R. Perdue, \& J. Sirgy (Eds.), Handbook of tourism and quality-of-life research: Enhancing the lives of tourists and residents of host communities (pp. 423-443). London: Springer Science+Business Media Publications.

Wall, G. (1982). Cycles and capacity: Incipient theory or conceptual contradiction? Tourism Management, 3(3), 188-192.

Wall, G., \& Mathieson, A. (2006). Tourism: Change, impacts, and opportunities. New York: Pearson Prentice Hall.

Weaver, D. (2000). A broad context model of destination development scenarios. Tourism Management, 21, 217-224.

Weaver, D. (2006). The 'plantation' variant of the TALC in the small-island Caribbean. In R. Butler (Ed.), The tourism area life cycle, Vol. 1: Applications and modifications (pp. 185-197). Clevedon: Channel View.

World Economic Forum. (2015). Travel and tourism competitiveness report 2015, growth through shocks. Geneva, Switzerland: the World Economic Forum.

WTTC. (2009). Travel \& tourism economic impact 2009 Macedonia. London, UK: World Travel \& Tourism Council.

WTTC. (2013). Travel \& tourism economic impact 2013 Macedonia. London, UK: World Travel \& Tourism Council.

Yang, J., Ryan, C., \& Zhang, L. (2014). Sustaining culture and seeking a Just Destination: Governments, power and tension - a life-cycle approach to analysing tourism development in an ethnic-inhabited scenic area in Xinjiang, China. Journal of Sustainable Tourism, 22(8), 1151-1174.

Zhang, H.Q., King C., \& Ap, J. (1999). An analysis of tourism policy development in modern China. Tourism Management, 20(4), 471-485.

Zhang, C., \& Xiao, H. (2014). Destination development in China: towards an effective model of explanation. Journal of Sustainable Tourism, 22, 214-233.

Zhong, L., Deng, J., \& Xiang, B. (2008). Tourism development and the tourism area life-cycle model: A case study of Zhangjiajie National Forest Park, China. Tourism Management, 29, 841-856. 